\title{
In vivo Activity of Silver Nanoparticles Against Pseudomonas aeruginosa Infection in Galleria mellonella
}

\author{
Luciana Thomaz ${ }^{1 \star \dagger}$, Luiz Gustavo de Almeida ${ }^{1 \dagger}$, Flávia R. O. Silva ${ }^{2}$, Mauro Cortez $^{3}$, \\ Carlos P. Taborda ${ }^{1,4}$ and Beny Spira ${ }^{1 *}$
}

${ }^{1}$ Department of Microbiology, Institute of Biomedical Science, University of São Paulo, São Paulo, Brazil, ${ }^{2}$ Nuclear and Energy Research Institute (IPEN), São Paulo, Brazil, ${ }^{3}$ Department of Parasitology, Institute of Biomedical Science, University of São Paulo, São Paulo, Brazil, ${ }^{4}$ Laboratory of Medical Mycology/LIM53, Faculty of Medicine, Institute of Tropical Medicine of São Paulo, University of São Paulo, São Paulo, Brazil

\section{OPEN ACCESS}

Edited by:

You-Hee Cho,

CHA University, South Korea

Reviewed by:

Wooseong Kim

Ewha Womans University,

South Korea

Roberto Di Marco,

University of Molise, Italy

${ }^{*}$ Correspondence:

Luciana Thomaz

lucithomaz@hotmail.com

Beny Spira

benys@usp.br

†These authors have contributed equally to this work

Specialty section:

This article was submitted to Antimicrobials, Resistance and

Chemotherapy,

a section of the journal

Frontiers in Microbiology

Received: 10 July 2020

Accepted: 16 October 2020 Published: 09 November 2020

Citation:

Thomaz L, Gustavo de Almeida L, Silva FRO, Cortez M, Taborda CP and Spira B (2020) In vivo Activity of Silver Nanoparticles Against Pseudomonas aeruginosa Infection in Galleria mellonella.

Front. Microbiol. 11:582107. doi: 10.3389/fmicb.2020.582107
Pseudomonas aeruginosa is an opportunistic pathogen associated with life-threatening nosocomial and community-acquired infections. Antibiotic resistance is an immediate threat to public health and demands an urgent action to discovering new antimicrobial agents. One of the best alternatives for pre-clinical tests with animal models is the greater wax moth Galleria mellonella. Here, we evaluated the antipseudomonal activity of silver nanoparticles (AgNPs) against P. aeruginosa strain UCBPP-PA14 using G. mellonella larvae. The AgNPs were synthesized through a non-toxic biogenic process involving microorganism fermentation. The effect of AgNPs was assessed through characterization and quantification of the hemocytic response, nodulation and phenoloxidase cascade. On average, $80 \%$ of the larvae infected with $P$. aeruginosa and prophylactically treated with nanoparticles survived. Both the specific and total larvae hemocyte counts were restored in the treated group. In addition, the nodulation process and the phenoloxidase cascade were less exacerbated when the larvae were exposed to the silver nanoparticles. AgNPs protect the larvae from $P$. aeruginosa infection by directly killing the bacteria and indirectly by preventing an exacerbated immunological response against the pathogen. Our results suggest that the prophylactic use of AgNPs has a strong protective activity against $P$. aeruginosa infection.

Keywords: Galleria mellonella, Pseudomonas aeruginosa, silver nanoparticles, hemocytes, kefir

\section{INTRODUCTION}

Pseudomonas aeruginosa is a $\gamma$-proteobacterium found in natural reservoirs of water, soil, plants and animals, being also common in hospital premises. This bacterium has the ability to colonize surfaces and medical equipment, frequently leading to nosocomial infections (Decraene et al., 2018). In humans, P. aeruginosa infections are associated with severe skin burns and is a major cause of death in patients with cystic fibrosis (Emerson et al., 2002; Rodríguez-Rojas et al., 2012). P. aeruginosa is classified as a serious health threat by the Center for Disease Control and Prevention (CDC) and due to its drug resistant nature is considered a Priority 1 critical pathogen by the World Health Organization (WHO) (Magiorakos et al., 2012). Most clinical strains of $P$. aeruginosa display resistance to several classes of antibiotics such as $\beta$-lactams, carbapenems, aminoglycosides, and fluoroquinolones (Potron et al., 2015). Colistin is a last- resort antibiotic used in P. aeruginosa therapy, but it displays nephro and neurotoxicity. Furthermore, strains of $P$. aeruginosa resistant 
to colistin have already been reported (Hill et al., 2014; Karaiskos et al., 2017). Hence, there is an urgent need for the screening and development of new antimicrobial drugs effective against $P$. aeruginosa. Silver (Ag) displays antibacterial activity and has been widely used throughout history in the fight against bacterial infections (Fox, 1968; Mathur et al., 2018). Silvercontaining products have been used in medical devices to prevent contamination with opportunistic pathogens such as Candida and Aspergillus (Jain et al., 2009). The use of silver in anti$P$. aeruginosa therapy began in 1968 with the introduction of silver nitrate for the prophylactic treatment of burn wounds (Fox, 1968). More recently, silver nanoparticles (AgNPs) have been devised to improve the physical, chemical, and biological properties of Ag. AgNPs display a strong antimicrobial activity even against bacteria resistant to multiple antibiotics, making it an alternative weapon in the fight against pathogenic microorganisms (Kalishwaralal et al., 2010; Rai et al., 2012; Mathur et al., 2018). Although the bactericidal properties of AgNPs have been demonstrated (Sondi and Salopek-Sondi, 2004; Markowska et al., 2013; Yan et al., 2018), the exact mechanism of action of these nanoparticles is still unclear. It has been suggested that AgNPs directly interact with the bacterial cell wall or that they release $\mathrm{Ag}^{+}$ions which in turn exert toxicity on the pathogen (Yan et al., 2018). AgNP causes the denaturation of the $30 \mathrm{~S}$ ribosome subunit, impairing the expression of essential proteins (Rai et al., 2012). It also binds to RNA and DNA molecules leading to the formation of nucleotide dimers (Sondi and Salopek-Sondi, 2004). On another level, AgNPs strongly bind membranal lipids, where they poke holes and affect the bacterial wall structure resulting in the leak of the intracellular content (Rai et al., 2012). AgNPs also interfere with cellular signaling by dephosphorylating tyrosine residues on key bacterial peptide substrates and ultimately inhibiting microbial growth (Shrivastava et al., 2007). Cellular oxidative stress is an indication of toxic effects caused by heavy metals ions, such as $\mathrm{Ag}^{+}$. At least part of the potent antibacterial, antifungal and antiviral activity of AgNPs is due to their ability to produce radical oxygen species (ROS) such as hydrogen peroxide $\left(\mathrm{H}_{2} \mathrm{O}_{2}\right)$, superoxide anion $\left(\mathrm{O}_{2}{ }^{-}\right)$, hydroxyl radical $(\mathrm{OH} \cdot)$, hypochlorous acid $(\mathrm{HOCl})$ and singlet oxygen (Wu et al., 2014).

A critical aspect in the evaluation of an antimicrobial drug is the pre-clinical test for effectiveness and toxicity in an animal model. Although rodents are the most common model for the investigation of pathogen-host interactions, they are costly and require a relatively complex infrastructure. A viable alternative is the use of invertebrates that in addition of supporting the $3 \mathrm{R}$ principle (reduction, refinement, and replacement) are also exempt from ethics committee approval. The greater wax moth, Galleria mellonella, exhibits specific characteristics that make it suitable for the study of host-pathogen interactions. This invertebrate has many advantages over other animal models (reviewed by Cutuli et al., 2019) and is becoming a major model of infection by pathogenic microorganisms. Their larvae can be incubated at $37^{\circ} \mathrm{C}$, and they display an innate immune response similar to that of vertebrates, which are in many aspects conserved in metazoans (Browne and Kavanagh, 2013; Wojda, 2017). Thus, G. mellonella is a simple, inexpensive and fast-testing in vivo model for studying microbial virulence and for screening new antimicrobial agents (Desbois and Coote, 2012; Hill et al., 2014). Indeed, several studies have already explored $G$. mellonella larvae as a model for P. aeruginosa infection (Miyata et al., 2003; Andrejko et al., 2014; Hill et al., 2014; MizerskaDudka and Andrejko, 2014; Beeton et al., 2015).

In the present study, we assessed the antibacterial activity of a new AgNP formulation against $P$. aeruginosa strain UCBPPPA14, using G. mellonella larvae as an infection model. This is a highly virulent strain in both animals and plants which carries two pathogenicity islands (He et al., 2004; Lee et al., 2006) and that is gradually substituting strain PA01 in $P$. aeruginosa pathogenicity studies (Mathee, 2018). A thorough analysis of the larvae immune response was conducted and a mechanism for the antipseudomonal activity of biogenic AgNPs is suggested.

\section{MATERIALS AND METHODS}

\section{Insects and Microorganisms}

The larvae of the greater wax moth Galleria mellonella (order Lepidoptera, family Pyralidae and subfamily Gallerinnae) were reared on artificial diet (pollen and honeybee manufactured by Apiário Seiva das Flores/São Paulo, Brazil) at $28.5^{\circ} \mathrm{C}$ in our animal facility. G. mellonella larvae in the final (7th) larval instar and weighing 150-220 mg were used in all experiments. Only larvae with intense movement and devoid of black spots in the cuticle were used. The colonies were routinely tested for the presence of pathogens, such as filamentous fungi. Although there are not formal ethical regulations on experimental work with $G$. mellonella, the ethical principles of reduction, refinement and replacement have been implemented throughout this study. The insects were sacrificed by freezing. It has been shown that food deprivation leads to increased infection susceptibility, due to the suppression of immune responses (Banville et al., 2012). To avoid this additional confounding effect, larvae were fed ad libitum for the duration of the study.

$P$. aeruginosa strain UCBPP-PA14 was routinely grown at $37^{\circ} \mathrm{C}$ in Lysogeny Broth (LB)/L-agar medium (Miller, 1992) or in Mueller-Hinton medium.

\section{Synthesis and Characterization of AgNP}

AgNPs were synthesized in the Biomaterials Laboratory, at the Science and Technology Material Center (CCTM) of the Nuclear and Energy Research Institute (IPEN) in São Paulo, Brazil. The green synthesis of silver nanoparticles was performed using a water kefir liquor, which is produced through the fermentation of a raw sugar solution containing kefir grains (consisting of polysaccharides and microorganisms). Kefir liquor contains ethanol, glycerol, lactic acid, acetic acid, mannitol, ethyl acetate, isoamyl acetate, ethyl hexanoate, ethyl octanoate, and ethyl decanoate (Laureys and De Vuyst, 2014). This is to the best of our knowledge the first time that fermenting kefir liquor has been used for the green synthesis of silver nanoparticles. The kefir grains were gently stirred (RW 20 digital, IKA, Germany) in deionized water for $1 \mathrm{~h}$ and sieved. This washing process was repeated thrice. The kefir fermentation was performed at room temperature, for $48 \mathrm{~h}$, where $200 \mathrm{~g}$ of kefir grains and $50 \mathrm{~g}$ of 
organic unrefined sugar cane were mixed in $500 \mathrm{ml}$ deionized water. The water kefir fermented liquor was centrifuged $(16,000$ $\times \mathrm{g}, 15 \mathrm{~min}, 4^{\circ} \mathrm{C}$ ) to obtain a cell-free supernatant (Solution A). For the green synthesis of silver nanoparticles, $10 \mathrm{ml}$ of Solution A were mixed with $0.01 \mathrm{~g}$ of $\mathrm{AgNO}_{3}$ (Sigma Aldrich), under ultrasonic agitation for $10 \mathrm{~min}$. The AgNPs were stored under refrigeration $\left(4^{\circ} \mathrm{C}\right)$ and protected from light until further use. The nanoparticles were characterized by transmission electron microscopy (TEM) (JEOL JEM 2100) at an accelerating voltage of $200 \mathrm{kV}$ and UV-Visible spectroscopy (Epoch 2 Biotech).

\section{Determination of AgNP Minimum Inhibitory Concentration (MIC)}

An inoculum of $10^{6}$ bacteria/ml was suspended in MuellerHinton medium containing increasing concentrations of silver nanoparticles $(0-10 \mu \mathrm{g} / \mathrm{ml})$ and grown for $24 \mathrm{~h}$ at $37^{\circ} \mathrm{C}$. The MIC was determined by measuring the optical density of the cultures at $600 \mathrm{~nm}$ (Andrejko et al., 2014). Experiments were performed three times independently.

\section{Toxicity of AgNPs in G. mellonella}

The toxicity assay was performed in vivo using G. mellonella larvae. Groups of 18 larvae were treated with one of the following concentrations of AgNPs: 25, 35, 50, 75, 85, and $100 \mathrm{mg} / \mathrm{K}$ and larvae survival was monitored for 8 days. Larvae that presented lack of movement and did not respond to touch were considered dead. Experiments were performed three times independently. The Spearman-Karber Method was used to estimate the Lethal Dose causing $50 \%$ mortality $\left(\mathrm{LD}_{50}\right)$ of $G$. mellonella larvae.

\section{Prophylactic Treatment}

Larvae were treated with either $5 \mu \mathrm{l}$ of $0.9 \% \mathrm{NaCl}$, Solution A, AgNP (5-25 mg/Kg) or $\mathrm{AgNO}_{3}(25 \mathrm{mg} / \mathrm{Kg})$ by injection into the haemocoel of the last right pro-leg, using a 10- $\mu$ l Hamilton microsyringe. The larvae were kept in Petri dishes and incubated at $37^{\circ} \mathrm{C}$, for $2 \mathrm{~h}$ before bacterial infection.

\section{Infection of larvae}

The external body of the larvae was sterilized with $70 \%$ ethanol. For the infection, 100 bacteria/10 $\mu l$ were injected intrahaemocoel in the last left proleg, and the larvae were incubated at $37^{\circ} \mathrm{C}$ in the dark. Higher doses of bacteria ( $>100 \mathrm{CFU}$ ) killed all larvae in less than $24 \mathrm{~h}$ (not shown). Three negative control groups-larvae inoculated with either $0.9 \% \mathrm{NaCl}$, or Solution A, or an untouched group in which the larvae were only rinsed with ethanol, were included in all experiments. The latter control group was omitted from the figures to avoid cluttering, but in all cases it showed essentially the same results as the $0.9 \% \mathrm{NaCl}$ or Solution A controls. The larvae were visually monitored for 4 consecutive days. Death was determined by the lack of movement in response to touch and by dark pigmentation on the larvae cuticle. Each treatment group contained at least 20 larvae and all experiments were performed at least three times.

\section{Galleria mellonella Survival Assay}

Larvae mortality was assessed by determining the percentage of survival over 4 days using a Kaplan-Meier plot and the Logrank test (GraphPad Prism 6.0.1, GraphPad Software, Inc., La Jolla, USA). larvae that did not respond to physical touch and showed strong pigmentation on the cuticle were considered dead. Each group consisted of 20 larvae, and each survival assay was performed three times, totalizing 60 larvae per group in total.

\section{Extraction of Hemolymph}

The larvae were punctured in the abdomen with the help of a sterile scissor. The hemolymph was collected in microtubes containing Insect Physiological Saline (IPS-150 mM NaCl, 5 $\mathrm{mM} \mathrm{KCl}, 0.1 \mathrm{M}$ Tris-HCl, $\mathrm{pH}$ 6.9) and $0.002 \%$ phenylthiourea (PTU) (Sigma-Aldrich). Samples used to assess ProPO activity were extracted in the absence of PTU, and all samples were kept on ice to prevent coagulation/melanization. Cells were then centrifuged for $5 \mathrm{~min}$ at $200 \times \mathrm{g}$ at $4^{\circ} \mathrm{C}$. The pellet was suspended in IPS and immediately used for hemocyte counting and to determine bacterial concentration $(\mathrm{CFU} / \mathrm{ml})$.

\section{Determination of Bacterial Load in G. mellonella}

larvae were bled 3, 6, 9, or $18 \mathrm{~h}$ following infection. Hemolymph was obtained as described above and plated on L-agar containing $25 \mu \mathrm{g} \mathrm{ml}^{-1}$ nalidixic acid. Plates were incubated overnight at $37^{\circ} \mathrm{C}$ and colonies were counted. This assay was performed three times with 16 larvae for each condition.

\section{Quantification of Hemocytes}

The number of hemocytes in G. mellonella was determined through total hemocyte count (THC), and differential hemocyte count (DHC). Hemocytes were collected at 3, 6, 9, and $18 \mathrm{~h}$ after infection and counted using a phase contrast microscope. Cell types were classified as follows: plasmatocytes (Pl), granular cells (Gr) oenocytoids (Oe), or spherulocytes (Sp). Pl and Gr were identified by the presence of small granules in both population types and an extensive cytoplasm spread (exhibited only by $\mathrm{Pl}$ ). Oe were identified by the presence of big cell bodies and big nuclei. Sp cells were identified by the presence of spherules, as described (Andrejko et al., 2014; Mizerska-Dudka and Andrejko, 2014; Wu et al., 2016). These experiments were performed three times with 16 larvae for each condition.

\section{Phenoloxidase Activity}

The larvae hemolymph was extracted and suspended in icecold IPS, without PTU. Two microliters of the suspension were diluted in $18 \mu \mathrm{l}$ Tris buffer saline (TBS) containing $5 \mathrm{mM} \mathrm{CaCl}_{2}$ and $2 \mathrm{mM}$ L-DOPA (Sigma - Germany), dissolved in $50 \mathrm{mM}$ sodium phosphate $\mathrm{pH}$ 6.5. Melanin formation was quantified by reading the absorbance at $490 \mathrm{~nm}$ in a spectrophotometer (Epoch 2 Biotech) over $90 \mathrm{~min}$, at 15 min intervals. Each assay was performed three times, with 16 larvae for each condition. 
A

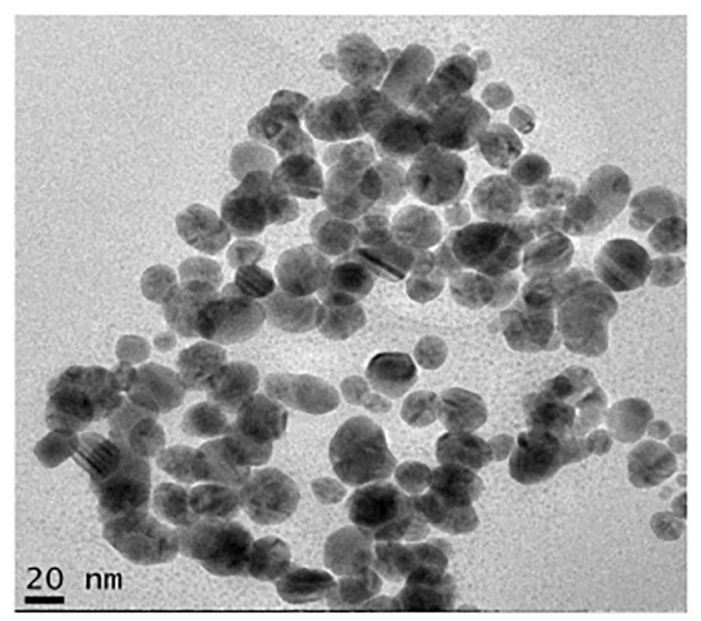

B

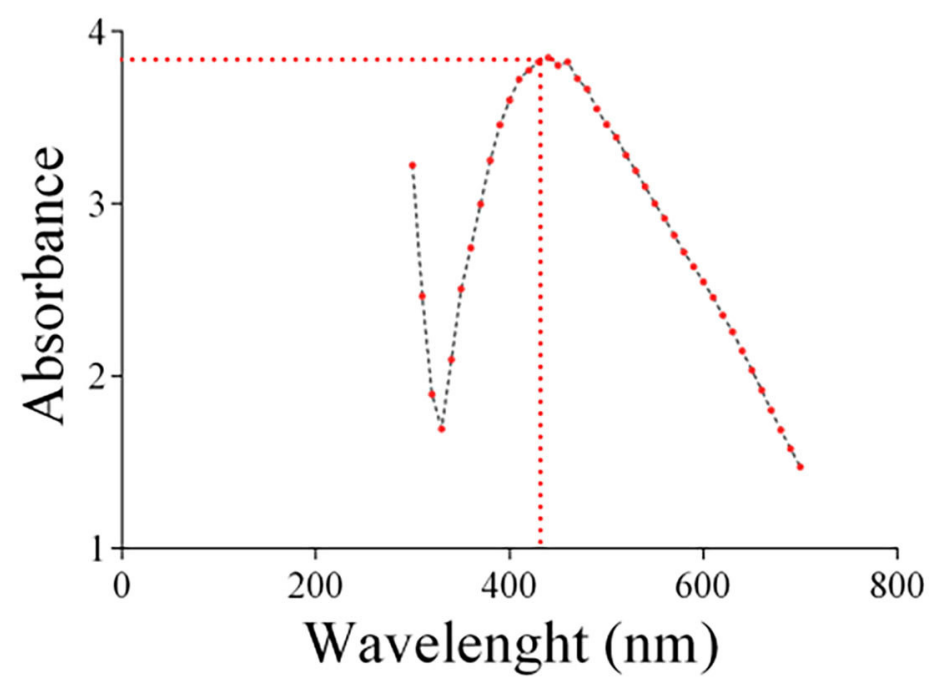

FIGURE 1 | (A) Representative TEM image of the AgNPs prepared and used in this study. (B) UVNIS absorption spectra of the silver colloid nanoparticles. The absorbance peak of the AgNPs corresponding to the surface plasmon resonance (SPR) of the nanoparticles was $435 \mathrm{~nm}$.

\section{Hemocyte Aggregation Assay (Nodulation Assay)}

Hemocytes were collected from non-infected and infected larvae and sampled on coverslips placed inside a 24 cell culture plate containing RPMI 1640, 10\% FBS and 1\% penicillin/streptomycin, and incubated at $30^{\circ} \mathrm{C}$ in a $\mathrm{CO}_{2}$ chamber. After $3 \mathrm{~h}$, the samples were washed with IPS. The hemocyte aggregates were counted in a DMI6000B/AF6000 microscope coupled to a DFC365FX camera with the help of the LAS software for image capture (Leica).

\section{Determination of Bacteria-Hemocytes Interaction}

The interaction between $P$. aeruginosa and hemocytes was assessed ex vivo and by immunofluorescence. Hemocytes were collected from non-infected larvae, suspended on a 24-cell culture plate filled with RPMI 1640, 10\% FBS and $1 \%$ penicillin/streptomycin and incubated at $30^{\circ} \mathrm{C}$ in a $\mathrm{CO}_{2}$ chamber at $5 \% \mathrm{CO}_{2}$ for $1 \mathrm{~h}$ to allow the attachment of the hemocytes to the well surface. Approximately 1,000 TAMRA (tetramethylrodhamine, $5 \mu \mathrm{M}$ )-stained bacteria were then added to the wells, each containing approximately $10^{6}$ hemocytes. After $3 \mathrm{~h}$ the samples were washed with IPS containing 100 $\mu \mathrm{g} / \mathrm{ml}$ gentamicin to remove non-internalized bacteria. The hemocytes were then fixed with $2 \%$ paraformaldehyde for 10 min, washed with TBS, and incubated for $15 \mathrm{~min}$ in $50 \mathrm{mM}$ ammonium chloride. The samples were then washed with TBS, and the cells were permeabilized with a solution containing $0.1 \%$ saponin, $0.1 \%$ sodium azide and $1 \%$ BSA. Next, the samples were stained with phalloidin-Alexa 488 (Thermo) for $2 \mathrm{~h}$ at $8^{\circ} \mathrm{C}$, washed with TBS and mounted on a slide with the help of Prolong-Diamond Antifade Mountant (Thermo). For the Live imaging time-lapse video, TAMRA-loaded bacteria were washed several times to discard any extracellular fluorescent marker and incubated with hemocytes previously plated in a MatTek $35 \mathrm{~mm}$ petri dish containing a $1.5 \mathrm{~mm}$ coverglass (MatTek Corporation, Ashland, MA, USA) and processed for the capturing of the $\mathrm{z}$ section. Fixed samples or Petri dishes were visualized on a fluorescence microscope (Leica DMI6000B/AF6000) coupled to a digital camera system (DFC 365 FX) by using Leica Application Suite X (LAS X) and Image J software (Schneider et al., 2012).

\section{Statistical Analyses}

All experiments were analyzed using GraphPad Prism 6.0.1 The statistical analyses were performed by ANOVA and RM ANOVA followed by $t$-test and the survival assays were analyzed by the Kaplan-Meier Curves and Mantel-Cox tests.

\section{RESULTS}

\section{Characterization of AgNPs}

AgNPs were synthesized by a biogenic process that uses kefir as described in Materials and Methods and characterized by TEM and UV/VIS absorption spectra (Figure 1). The diameter of a typical AgNP was about $20 \mathrm{~nm}$. For two months, once a week, the stability of the silver nanoparticles was monitored. AgNPs were highly stable, alterations in color or visual aggregation were never observed. The absorbance peak of the AgNPs was at $435 \mathrm{~nm}$ (Figure 1B), which corresponds to the surface plasmon resonance (SPR) of the nanoparticles. It is worth noticing that the process used for AgNP synthesis is non-toxic and inexpensive, being an alternative to physico-chemical methods that are costly and potentially toxic (Singh et al., 2015). 


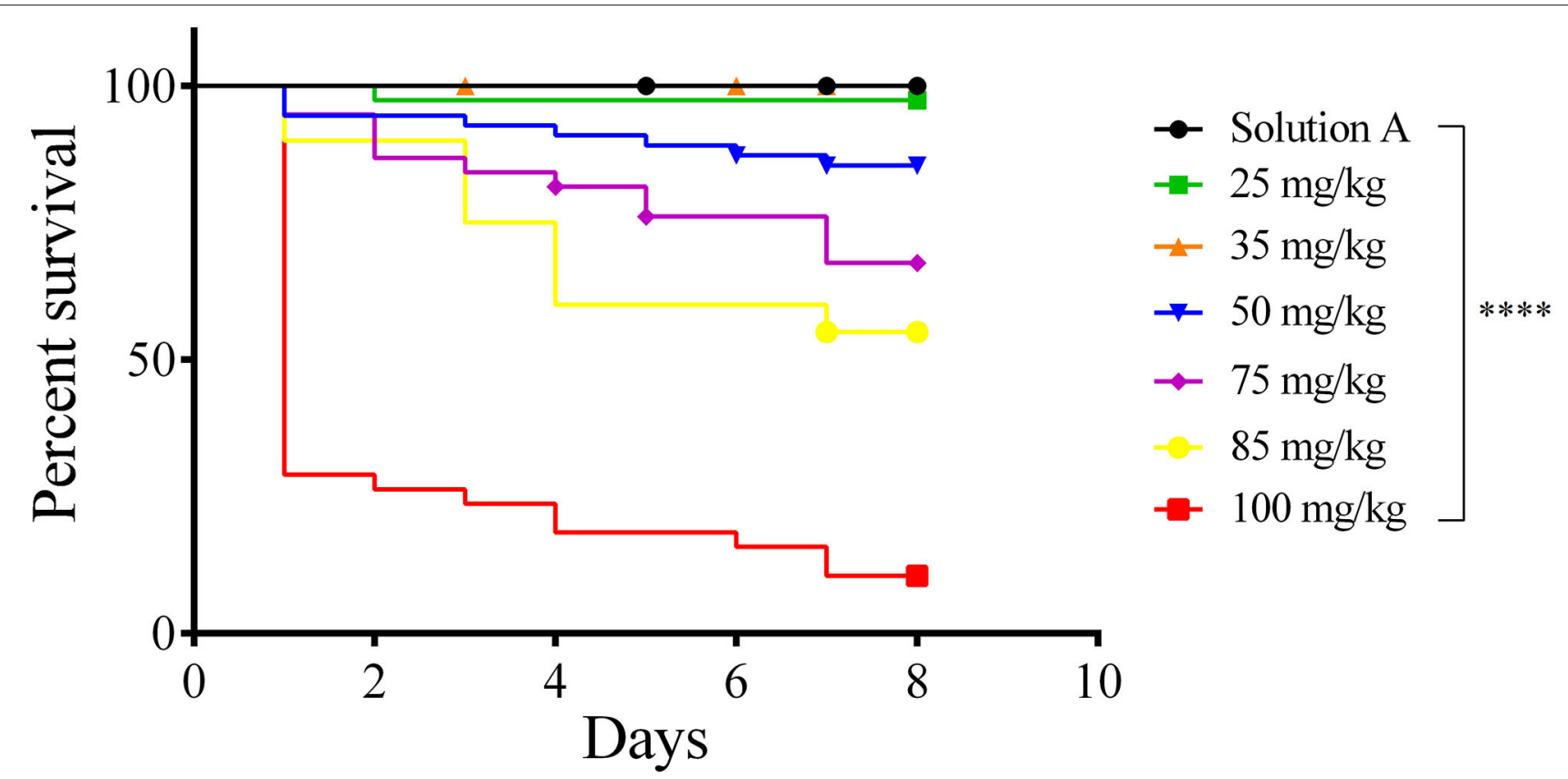

FIGURE 2 | Survival curve (Kaplan-Meier and Mantel Cox). Toxicity of AgNP in Galleria mellonella. Groups of 18 larvae each were treated with 25-100 mg/Kg of larvae tissue. The control groups were Solution A (black line) and Sham (not shown). Larvae were incubated at $37^{\circ} \mathrm{C}$ and their viability was followed for 8 days. Each line represents the mean of three independent experiments. ${ }^{\star \star \star \star} p<0.0001$.

\section{Minimal Inhibitory Concentration of AgNP}

AgNP antibacterial activity against $P$. aeruginosa (strain PA14) was evaluated in a MIC assay in vitro. PA14 is a highly virulent $P$. aeruginosa clinical isolate. This strain is a representative of the most common clonal group of this bacterial species (Wiehlmann et al., 2007). Increasing concentrations of AgNPs were added to a PA14 culture in $\mathrm{MH}$ medium that was subsequently grown for $24 \mathrm{~h}$. The MIC of our AgNPs was $2 \mu \mathrm{g} / \mathrm{ml}$, slightly higher than the $1.06 \mu \mathrm{g} / \mathrm{ml}$ reported by Pompilio et al. (2018) (P. aeruginosa strains PA14 and AC12A) but significantly lower than the MIC of AgNPs on P. aeruginosa reported by others: $8 \mu \mathrm{g} / \mathrm{mL}$ (strainPA01) (Radzig et al., 2013), $16 \mu \mathrm{g} / \mathrm{mL}$ (Wypij et al., 2018) (strain ATCC10145) and $14 \mu \mathrm{g} / \mathrm{mL}-29 \mu \mathrm{g} / \mathrm{mL}$ (strain CCM3955) (Guzman et al., 2012), $2.48 \mu \mathrm{g} / \mathrm{mL}$ (clinical isolates) (Liao et al., 2019).

\section{Toxicity of AgNPs in G. mellonella larvae}

To test whether our AgNP preparation bears toxicity against $G$. mellonella larvae, a toxicity assay with increasing concentrations of AgNPs (25, 35, 50, 75, 85, and $100 \mathrm{mg} / \mathrm{Kg}$ of larvae) was conducted (Figure 2). Larvae viability was observed for 8 consecutive days. No toxicity was observed at concentrations below $35 \mathrm{mg} / \mathrm{Kg}$. The $\mathrm{LD}_{50}$ of this AgNP formulation is 68.70 $\mathrm{mg} / \mathrm{Kg}$ of larvae.

\section{Protective Effect of AgNP on G. mellonella Infected With $P$. aeruginosa}

A preliminary assay showed that a concentration of $25 \mathrm{mg} / \mathrm{Kg}$ AgNPs was required to confer on the larvae protection against
P. aeruginosa ( $p=0.0001$, Logrank (Mantel-Cox) and KaplanMeier tests), while lower concentrations-5-20 mg/Kg-were not sufficient to kill the bacteria (Figure 3A). In addition, no toxic effect against $G$. mellonella could be observed at this concentration. Therefore, $25 \mathrm{mg} / \mathrm{Kg}$ was chosen as the working concentration of AgNPs. A thorough examination of the prophylactic effect of AgNPs or $\mathrm{AgNO}_{3}$ followed (Figure 3B). A group of larvae was inoculated with silver nanoparticles $2 \mathrm{~h}$ prior to bacterial infection. At time $0 \mathrm{~h}$, the larvae were infected with $100 \mathrm{P}$. aeruginosa cells. larvae that were not exposed to the prophylactic AgNPs treatment (group 1 - PA14, group 2 - PA14 + Sol. A, group 3 - PA14 + 0,9\% $\mathrm{NaCl}$ and group 4 - PA14 $+\mathrm{AgNO}_{3} /$ saline) exhibited disease symptoms (slow movement, loss of turgor and body darkening), and died during the first $24 \mathrm{~h}$ following infection. Eighty percent of the larvae pre-treated with $25 \mathrm{mg} / \mathrm{Kg}$ AgNPs and then challenged with $P$. aeruginosa were still alive 4 days after infection $(p=0.0001$, Log-Rank - Mantel Cox and Kaplan-Meier test). Interestingly, 25 $\mathrm{mg} / \mathrm{Kg} \mathrm{AgNO}_{3}$ did not confer protection on the larvae infected with $P$. aeruginosa.

\section{P. aeruginosa Growth Inside G. mellonella}

The progress of infection was followed by counting $P$. aeruginosa $\mathrm{CFU}$ in the hemolymph of the infected larvae. Figure $4 \mathrm{~A}$ shows that in the group pre-treated with AgNPs no bacteria were observed at any time $(p<0.0001$; Two-Way ANOVA followed by $t$-test). However, in the larvae that did not receive the prophylactic treatment there was a steady increase in bacterial concentration $(p<0.0001$; Two-Way ANOVA followed by $t$-test). Figure $4 \mathrm{~B}$ shows the interaction between bacteria 
A

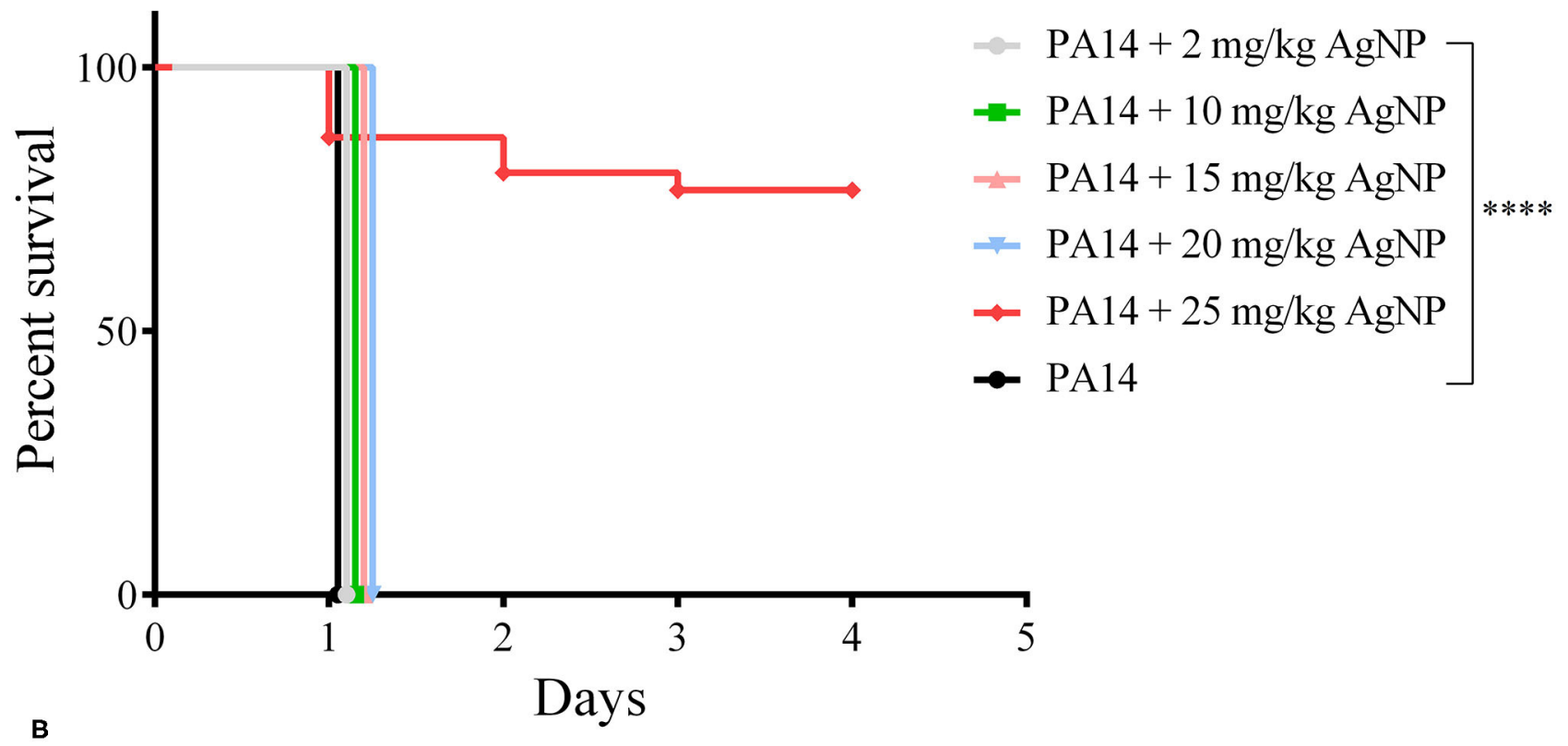

B

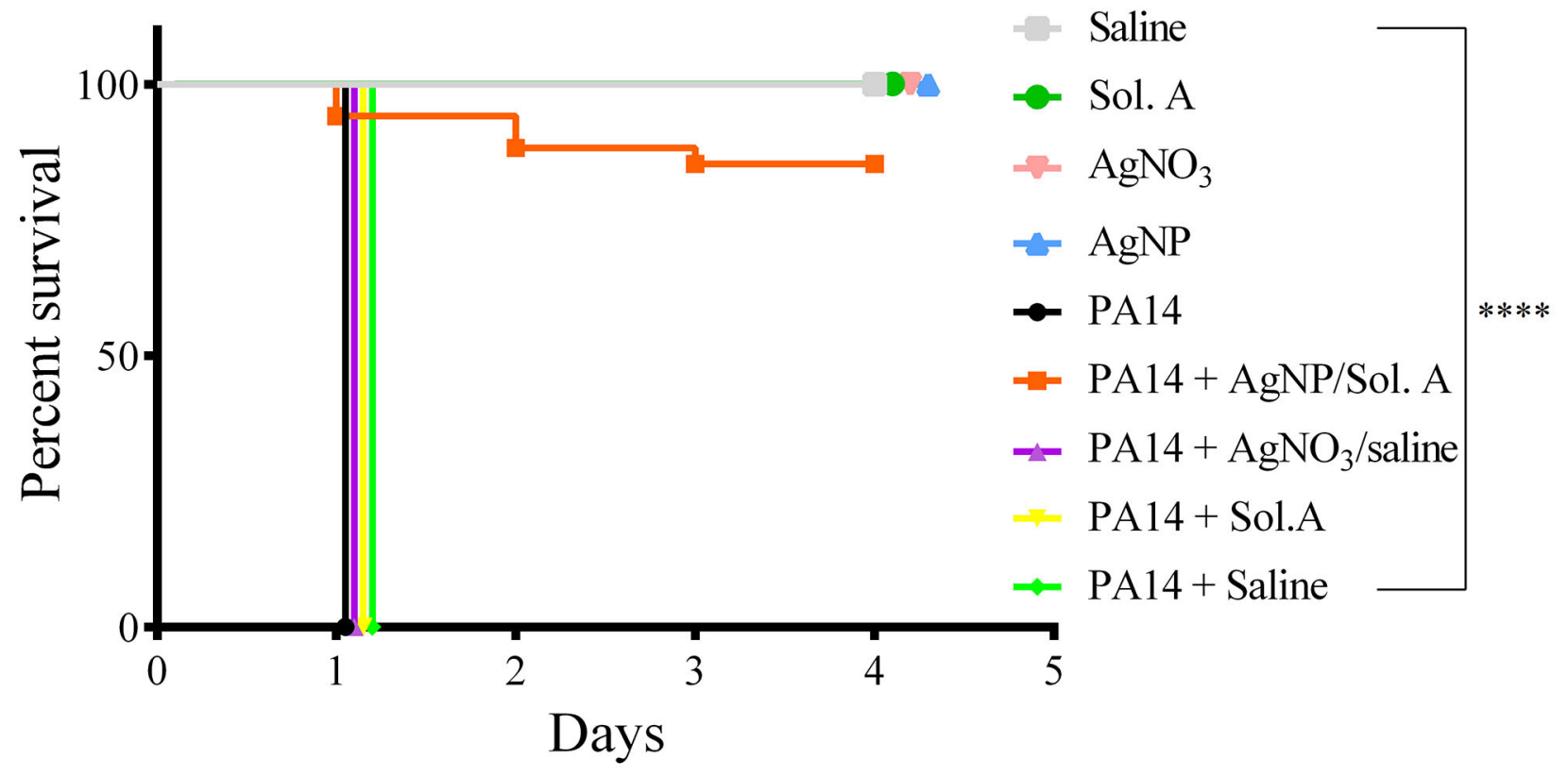

FIGURE 3 | Survival curves (Kaplan-Meier and Mantel Cox). (A) Protective effect of AgNPs in G. mellonella infected with P. aeruginosa. Groups of 20 larvae each were treated prophylactically for $2 \mathrm{~h}$ before infection, with $5-25 \mathrm{mg} / \mathrm{Kg}$ AgNPs per larva. The larvae were then infected with $100 \mathrm{CFU}$ of $P$. aeruginosa strain PA14. The black line represents larvae infected with PA14 in the absence of any prophylactic treatment. (B) Groups of 20 larvae were prophylactically treated with $25 \mathrm{mg} / \mathrm{Kg}$ AgNPs, Solution A, Saline or $\mathrm{AgNO}_{3}$. Two hours later, they were infected with 100 P. aeruginosa cells. The control groups were: Saline (gray line); Sol. A (green); $\mathrm{AgNO}_{3}$ (pink); AgNPs (blue). All larvae groups in $\mathrm{A}$ and $\mathrm{B}$ were incubated at $37^{\circ} \mathrm{C}$ and their viability was followed for 4 days. Each line represents the mean of three independent experiments. ${ }^{\star \star \star \star} p<0.0001$.

stained with TAMRA supravital staining (PA14/TAMRA) and hemocytes. It can be observed that the hemocytes internalized the bacteria, which kept growing inside the hemolymph.
The presence of bacteria inside the cells was confirmed by a $\mathrm{Z}$ section of an infected cell sample (see video in the Supplementary Material). 
A

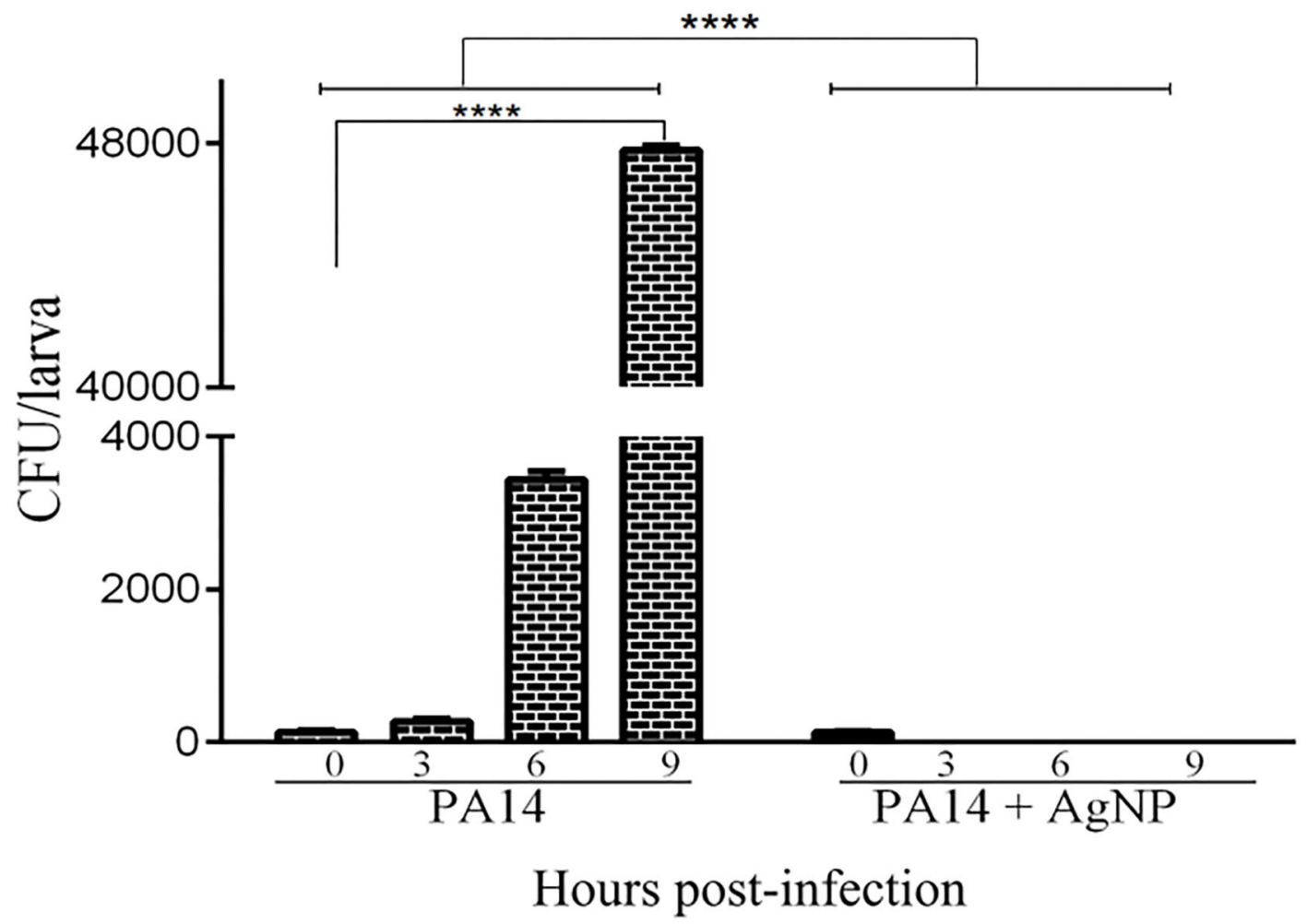

B
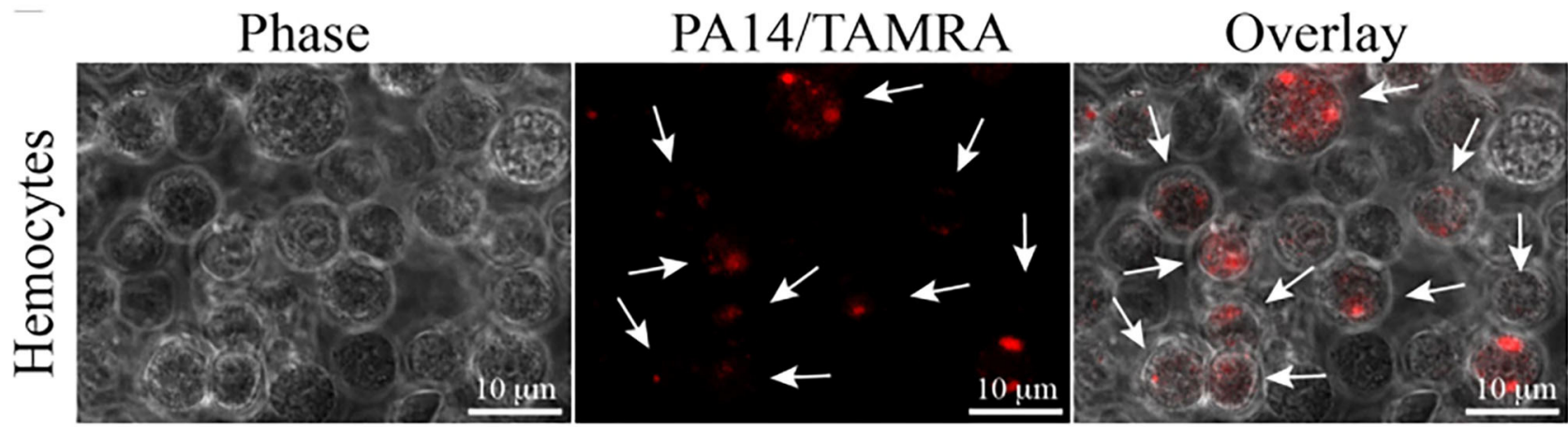

FIGURE 4 | Bacterial growth in the haemolymph of infected larvae. (A) 16 larvae were pre-treated with AgNPs and inoculated with P. aeruginosa. Zero, three, six, and nine hours following infection, the larvae haemolymph was extracted and plated on L-agar plates containing $25 \mu \mathrm{g} / \mathrm{ml}$ nalidixic acid. Following a $24 \mathrm{~h}$ incubation at $37^{\circ} \mathrm{C}$ the CFU on the plates were counted. Each bar represents the mean of three independent experiments. ${ }^{\star * \star *} p<0.0001$ (ANOVA and RM ANOVA followed by $t$-test). (B) Microscopic images of hemocytes from G. mellonella internalized with PA14. Bacteria cells were stained with TAMRA. Scale bars 10 $\mu$ m. White arrowheads point to bacteria inside the hemocytes. Photos are representative of three independent experiments.

\section{Hemocyte Quantification and Characterization}

Alterations in total hemocyte density (THC) and differential hemocyte density (DHC) are factors that indicate the larvae response to bacterial infection as hemocytes play an important role in the fight against pathogens (Bergin et al., 2006; Coates et al., 2019). Though not all hemocytes are directly involved in phagocytosis, overall they act together to strengthen the immune response (Browne et al., 2013; Wojda, 2017). Hemocyte density was evaluated by counting the different cell types in a hemocytometer chamber under a bright field microscope. Figure 5A displays a representative micrograph containing the 
A

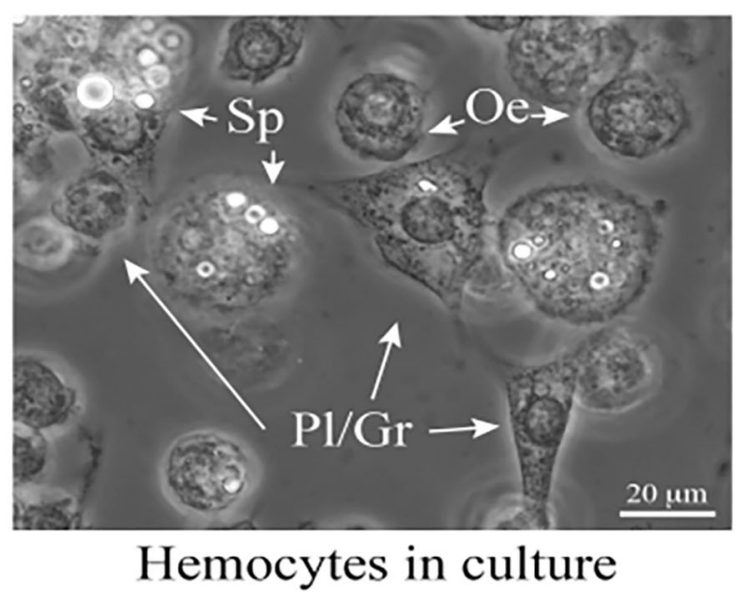

B

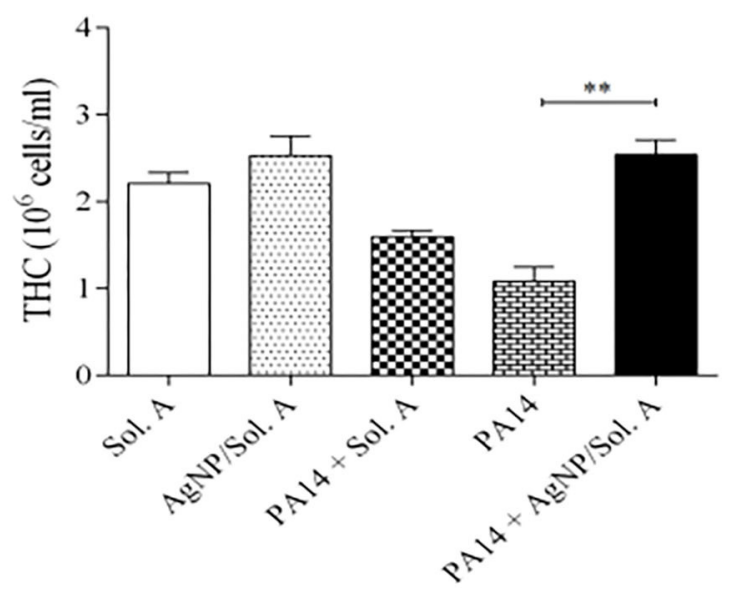

c
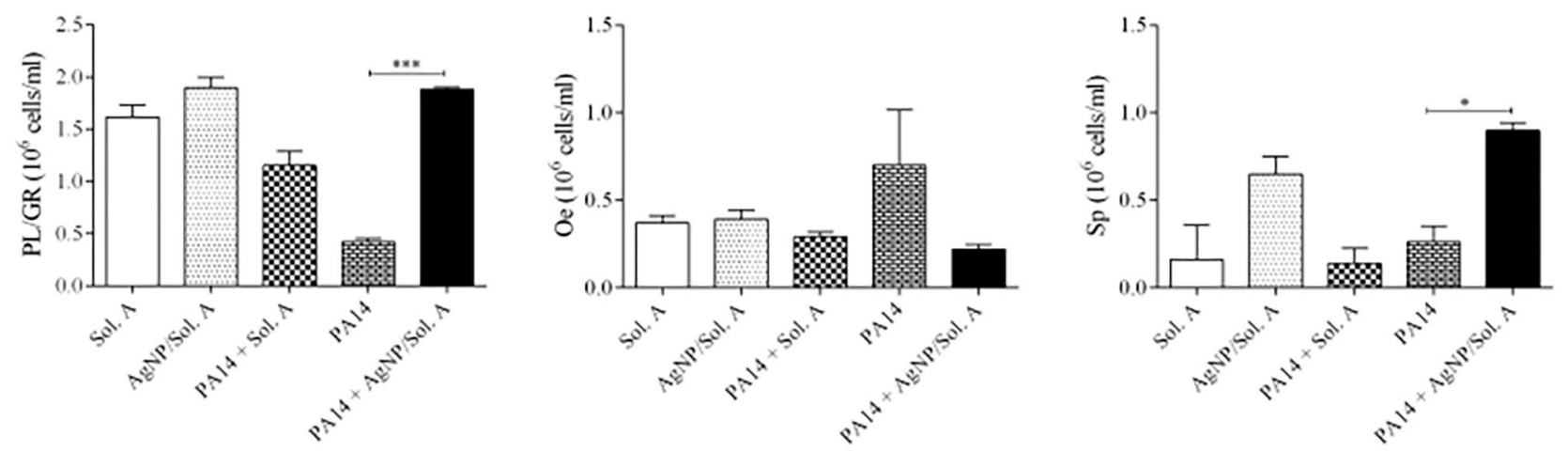

FIGURE 5 | (A) Microscopic images of Galleria mellonella hemocytes. Bar = $20 \mu \mathrm{m}$. White arrowheads point to hemocytes, PI/Gr, plasmatocytes/granular cells; Sp, spherulocytes, Oe, oenocytoids. (B) Total Hemocyte Count (THC) and (C) Differential Hemocyte Count (DHC) of circulating hemocytes in larvae prophylactically treated for $2 \mathrm{~h}$ with Solution A or AgNP/Sol. A and then infected for $18 \mathrm{~h}$ with $\mathrm{P}$. aeruginosa cells. The first and second bars represent larvae treated with Sol. A and AgNP/Sol. A, respectively (negative controls). The third bar represents larvae infected with bacteria (PA14) in the presence of Sol. A. The fourth bar corresponds to larvae infected with bacteria suspended in saline and the fifth bar corresponds to larvae pre-treated with AgNP/Sol. A for $2 \mathrm{~h}$ and then challenged with bacteria. Each bar represents the mean and standard deviation of three independent experiments, 16 larvae were used in each condition. Asterisks denote statistically significant differences. ${ }^{\star \star} p=0.0041 ;{ }^{* \star *} p=0.0003$, and ${ }^{\star} p=0.0116$ (ANOVA and RM ANOVA followed by $t$-test).

hemocyte types present in the larvae: plasmatocytes $(\mathrm{Pl})$, granular cells $(\mathrm{Gr})$, oenocytoids $(\mathrm{Oe})$ and spherulocytes $(\mathrm{Sp})$. Figure 5B shows the THC at $18 \mathrm{~h}$ following the beginning of infection. larvae infected with $P$. aeruginosa (bricked and chessboardlike bars in the figure) showed reduced levels of hemocytes when compared to the larvae prophylactly treated with AgNPs (PA14+AgNP/Sol. A, solid black bar) ( $p=0.0041$; ANOVA and Tukey's followed by $t$-test).

The differential hemocyte count (DHC) of circulating hemocytes showed that the phagocytic population $(\mathrm{Pl} / \mathrm{Gr})$ of larvae infected with $P$. aeruginosa but not treated with AgNPs was lower than in the AgNP-treated group (Figure 5C, compare bricked and chessboard-like bars with solid black bar, $p=0.0003$, ANOVA and Tukey's followed by $t$-test). Although there were not statistically significant differences in the oenocytoid population across the experimental groups, the phenoloxidase activity and microscopy analysis revealed that the infected groups (PA14 and PA14 + Sol. A) displayed the highest level of black cell aggregates (Figure 7B) and the highest ProPo activity rate (Figure 5Abricked and chessboard-like bars), both of which are directly related to an increment in oenocytoids Finally, the level of spherulocytes in the infected group pre-treated with AgNPs was higher than in the other groups $(p=0.0116$; ANOVA and Tukey's followed by $t$-test) (Figure 5C). Though spherulocytes are apparently not directly involved in the insect immune response, these cells may contribute to larvae protection and survival by increasing their ability to scavenge nutrients ( $\mathrm{Wu}$ et al., 2016; Wojda, 2017). It should be noted that larvae treated 
with Sol. A or AgNPs + Sol. A alone showed similar levels of THC when compared to the sham group - larvae that were not manipulated (data not shown), indicating that the AgNPs do not exert adverse effects on hemocytes.

\section{Induction of Phenoloxidase Activity}

In invertebrates, the first step in the immune response cascade is the activation of phenoloxidase (PO), which has a strong cytotoxic effect against non-self molecules (Wojda, 2017). The level of PO activation in larvae infected with $P$. aeruginosa and pre-treated with AgNPs was evaluated (Figure 6A). The hemolymph extracted from infected larvae displayed a high PO activity throughout the experiment. On the other hand, the group pre-treated with AgNPs showed a PO activity similar to that of the non-infected groups (compare PA14 and PA14 + Sol. A bars with PA14+AgNP/Sol. A solid black bar, $p=0.0031$, ANOVA followed by $t$-test). Figure 6B displays representative pictures of PO within hemocytes synthesized in response to PA14 infection. The dark spots result from the activation of the PO cascade.

\section{Quantification of Cell Aggregates and Nodulation}

The formation of hemocyte clusters, that contain microorganisms and occurs during the larvae healing process was visually followed under a microscope. Figure 7A shows the quantification of cell clusters, each containing at least 8 cells. The number of clusters was significantly higher in the larvae infected with $P$. aeruginosa than in larvae pre-treated with AgNPs [compare PA14 (bricked bar) or PA14 + Solution A (stripped bar) with PA14+AgNP/Sol. A (solid black bar), $p=0.001$, ANOVA followed by $t$-test]. Figure $7 \mathbf{B}$ shows representative images of cell clusters.

\section{DISCUSSION}

A major advantage in using insects as model organisms is that the innate immune system of these invertebrates is functionally similar to that of mammals (Browne et al., 2013). Accordingly, human pathogens display comparable levels of virulence and susceptibility when used to infect $G$. mellonella larvae or mammals (Desbois and Coote, 2012). It has been shown that 25 PA14 bacteria were sufficient to kill G. mellonella in $48 \mathrm{~h}$ (Jander et al., 2000; Hill et al., 2014). Similarly, in the present study, we showed that $100 \mathrm{CFU}$ of strain PA14 were sufficient to kill all larvae in the first $24 \mathrm{~h}$. Higher amounts of bacteria killed the larvae in less than $12 \mathrm{~h}$ (not shown). It has also been shown that the MICs of other antipseudomonal drugs were equivalent in G. mellonella and in human patients (Hill et al., 2014). Our formulation of AgNPs displayed a strong in vitro bactericidal effect against strain PA14, with a MIC of $2 \mu \mathrm{g} / \mathrm{ml}$. The MICs of AgNPs in $P$. aeruginosa thus far reported in the literature were: $1.06-4.25 \mu / \mathrm{ml}$ in strains PA14, AC12A, and DIN1 of $P$. aeruginosa (Pompilio et al., 2018); $2 \mu / \mathrm{ml}$ in an environmental $P$. aeruginosa (Kora and Arunachalam, 2011); 3.4-27 $\mu / \mathrm{ml}$ in a clinical isolate of $P$. aeruginosa or in strain CCM3955 (Panáček et al., 2018); $8 \mu \mathrm{g} / \mathrm{ml}$ (P. aeruginosa PAO1) (Radzig et al., 2013); $10 \mu / \mathrm{ml}$ in P. aeruginosa PA14 (da Silva et al., 2020); $14 \mu \mathrm{g} / \mathrm{ml}$ (P. aeruginosa strain CCM 3955) (Guzman et al., 2012); $16 \mu \mathrm{g}$ /ml (P. aeruginosa ATCC 10145) Wypij et al. (2018); $8 \mathrm{mg} / \mathrm{ml}$ ( $P$. aeruginosa clinical isolate) Nour El Din et al. (2016) and $2.48 \mu \mathrm{g} / \mathrm{ml}$ (clinical isolates) (Liao et al., 2019). Thus only one out of 9 studies (Pompilio et al., 2018) have reported an AgNP preparation with a lower MIC than ours.

Here, the in vivo minimal AgNPs concentration required to protect $G$. mellonella larvae against $P$. aeruginosa was 25 $\mathrm{mg} / \mathrm{Kg}$. A prophylactic treatment using this concentration of AgNPs resulted in the survival of $80 \%$ of the infected larvae. The discrepancy between in vitro and in vivo MICs is normal and has been reported elsewhere (Pompilio et al., 2018). A basic difference between in vivo and in vitro tests is that in the former endogenous molecules may interfere with the tested compound activity. For instance, circulating albumin in mammals blood is known to interact with many different molecules, reducing their effectiveness (Yamasaki et al., 2013).

The immune response of insects is a multi-step process, activated upon pathogen invasion, that can be followed through the analyses of a variety of endpoints, such as larvae survival, hemocyte characterization and quantification, presence of nodulation and melanization, presence of antimicrobial peptides, ROS synthesis and lactate dehydrogenase activity (Rowan et al., 2009; Browne and Kavanagh, 2013). The cellular response is mediated by six different types of hemocytes, with three of them being the most relevant: granular cells, plasmatocytes and oenocytoids. Granular cells and plasmatocytes are adherent cells that possess the ability to carry out phagocytosis, encapsulation and nodulation of the pathogen. Though oenocytoids are also able to carry out phagocytosis (Wu et al., 2016), their main functions are the synthesis and transport of mucopolysaccharides and, most importantly, the secretion of serine protease associated with phenoloxidase (PO) activity (Tokura et al., 2014; Wojda, 2017). Given the crucial role that hemocytes play in the response to invading agents, the investigation of hemocyte build-up reveals important clues about the modulation of G. mellonella immune system. The proportion of each hemocyte type has been shown to vary widely during the 7 stages of larval development (Bergin et al., 2006). Pre-hemocytes have a short half-life, which explains their absence in this as well as in other studies (Labbé and Saleh, 2008; Dubovskiy et al., 2013). The distribution of different hemocyte types observed in the present study showed a considerable fluctuation but is consistent with what has been reported elsewhere (Bergin et al., 2006). We showed that the concentration of total hemocytes in larvae treated prophylactically with AgNPs was higher than in the nontreated larvae. The restoration of THC in the AgNP-treated larvae is likely to be associated with bacterial clearance from the larvae body. Similarly, Rowan et al. (2009) demonstrated that the administration of $\mathrm{AgNO}_{3}$ derivatives prior to infection with Candida albicans protected G. mellonella. The efficacy of these compounds were attributed to an increase in hemocyte counting, mostly of phagocytic cells.

It has been shown that $P$. aeruginosa infection in G. mellonella causes morphological and ultrastructural changes in hemocytes, including the formation of autophagic vacuoles, indicating that $P$. aeruginosa actively destroys hemocytes (Andrejko et al., 2014; Mizerska-Dudka and Andrejko, 2014). A similar effect was shown in this study, as our hemolymph microscopic analyses 
A

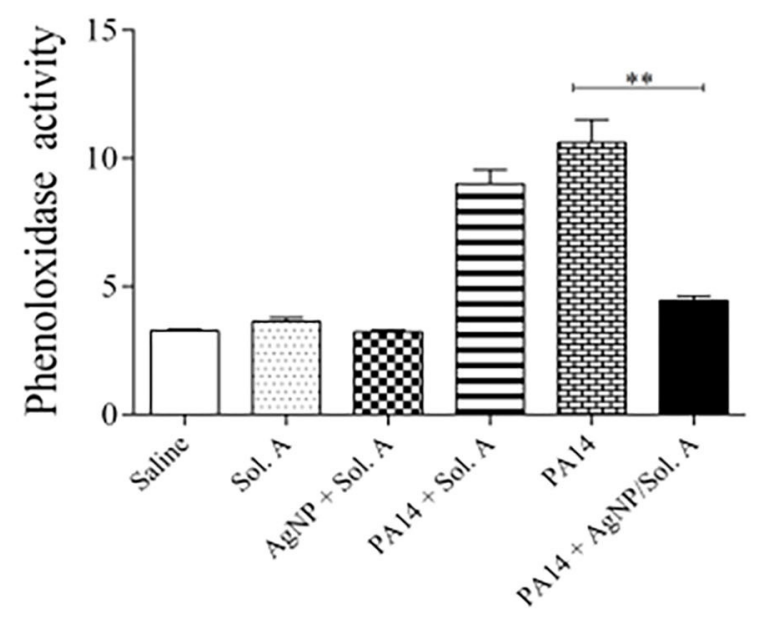

B

40X objective
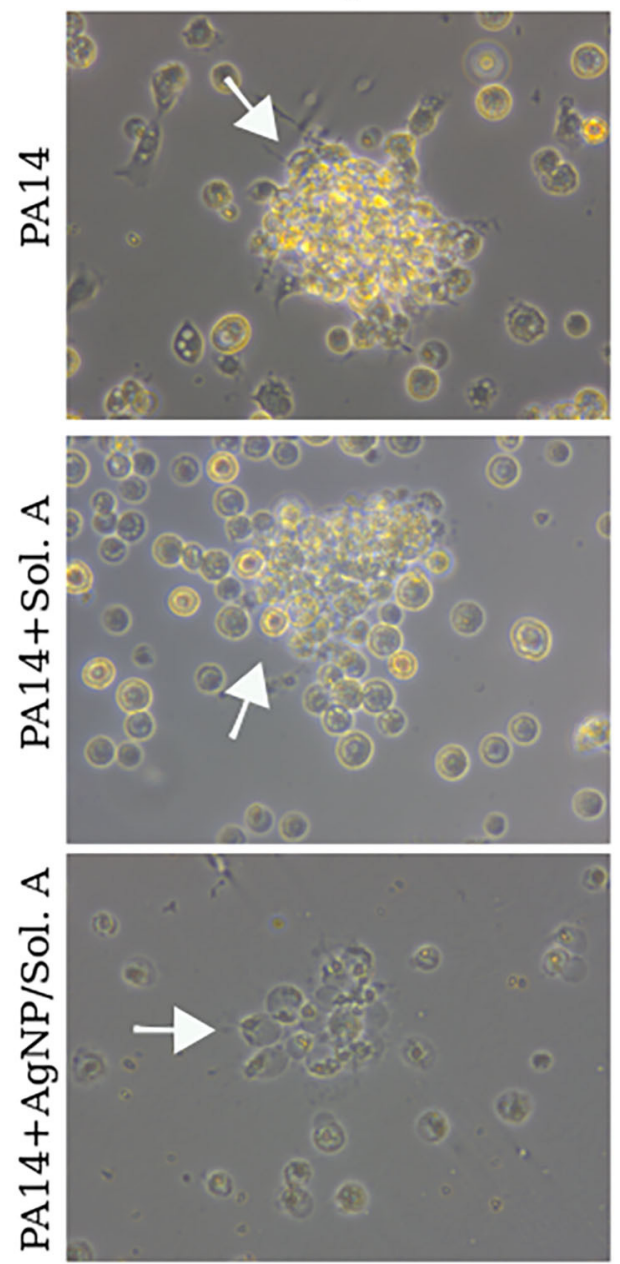

10X objective
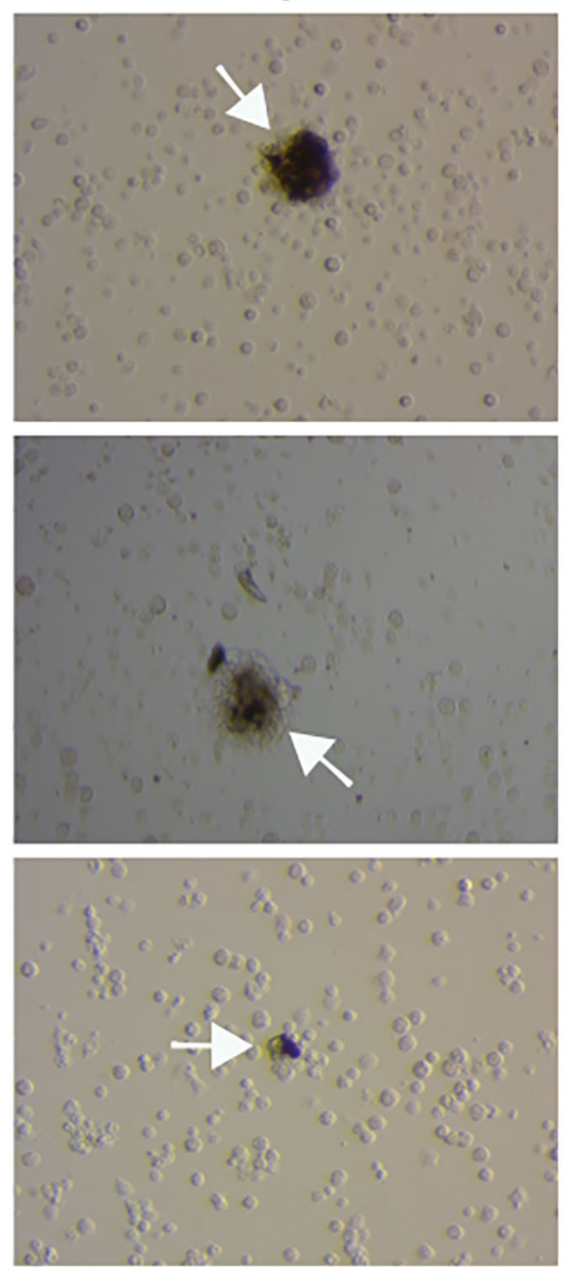

FIGURE 6 | (A) Phenoloxidase activity at $9 \mathrm{~h}$ following infection with P. aeruginosa was determined by analyzing the rate of melanization at 0, 15, 30, 45, 60, 75, and $90 \mathrm{~min}$. The bars representations are as described in the legend of Figure 4. Each bar represents the mean and standard deviations of three independent experiments. Each treatment condition contained 16 larvae. ${ }^{* *} p=0.0031$ (ANOVA and RM ANOVA followed by $t$-test). (B) Microscope images showing cell aggregates on the left and black aggregates on the right (white arrows) resulting from PO activity. 
A

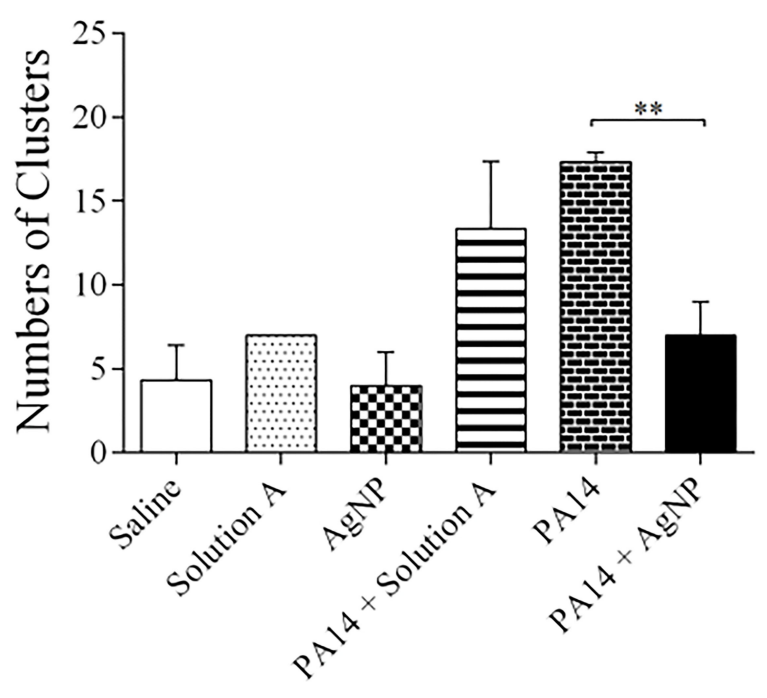

B
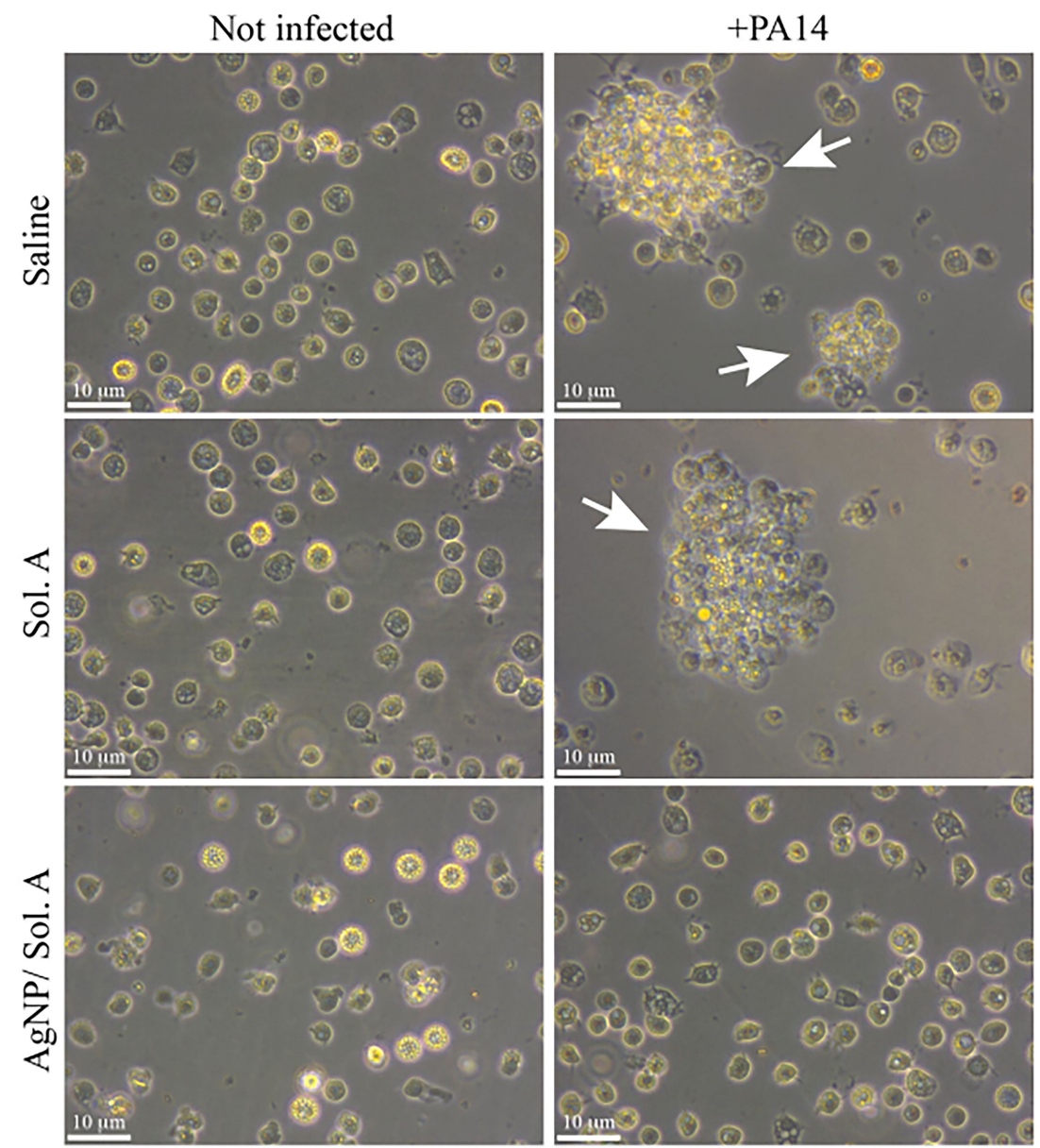

FIGURE 7 | (A) Quantification of cell clusters during the nodulation process. The number of clusters was determined by counting cell aggregates (nodulation) under a light microscope. The bars representations are as described in the legend of Figure 4. Each bar represents the mean and standard deviations of three independent experiments. Each treatment condition contained 16 larvae. ${ }^{* *} p=0.0010$ (ANOVA and RM ANOVA followed by $t$-test). (B) Representative microscope images of cell nodulation. Micrographs on the left show hemocytes extracted from non-infected larvae and micrographs on the right show hemocytes from larvae treated with PA14 bacteria. White arrows indicate aggregates of cells. 
revealed the presence of phagocytic vacuoles and membrane alterations akin to the spreading of phagocytic vertebrate cells. The pathogen ability to invade the host is associated with virulence factors which ultimately elicit the insect cellular and humoral immune response. Plasmatocytes and granular cells are the main phagocytic cells that engulf and kill invading bacteria. These cells undergo cytoskeleton rearrangement, followed by extensive pseudopodia. The final step of this process is the phagocytosis of the invading pathogen or its envelopment in a nodular or capsular structure (Wojda and Jakubowicz, 2007; Mizerska-Dudka and Andrejko, 2014; Wojda, 2017). The microscope analyses revealed that prophylactic administration of AgNPs reduced or eliminated the presence of bacteria in the larva body resulting in less membrane disruption.

Our results suggest that the role of AgNPs on the protection against $P$. aeruginosa infection was double-fold: they actively killed the invading bacteria and indirectly act upon the larvae immune system, curbing an exacerbated immune response caused by the production of quinones and melanization that may eventually harm the host tissues. However, it is still possible that the alleviation of the immune response could be entirely due to the elimination of $P$. aeruginosa cells by the bactericidal activity of AgNPs.

In all tested groups hemocytes surrounded the $P$. aeruginosa cells, forming nodules. There was a positive correlation between the number of nodules and bacteria counts in the larvae. Accordingly, larvae pre-treated with AgNPs presented less bacteria and accumulated fewer nodules, corroborating the association between the absence of nodules and bacterial clearance (Hill et al., 2014). The cellular response occurs concomitantly to the humoral response, which is mediated by defense molecules, such as antimicrobial peptides, and oxygen and nitrogen free radicals (Rowan et al., 2009). In addition to these mechanisms, insects display a complex enzymatic cascade that results in melanization, a coagulation process that is characterized by the formation of capsules of dark composition that engulf the invading agent (Tokura et al., 2014). Prophylactic treatment with AgNPs treatment has also reduced the level of melanization and PO activity. This achievement is of utmost importance as high levels of melanization results in the death of both host and pathogen (Tokura et al., 2014).

Another type of hemocyte present in the nodules is the oenocytoid. The concentration of these cells was similar in the AgNP-treated group and in the non-infected controls. The oenocytoids are involved in the production of serine proteases that activate the phenoloxidase cascade, whose final product is melanin (Tokura et al., 2014). Low levels of these cells might explain the low phenoloxidase activity and the consequent reduction of clusters observed in PA14-infected larvae pretreated with AgNPs.

Nanoparticles have many advantages over conventional antimicrobial agents, including antibiotics. They are usually inexpensive and are simple to prepare. The green synthesis with kefir used in this study simplifies and cheapen even more the process of AgNP synthesis. Due to their small dimensions, nanoparticles penetrate easily in the bacterial cell or in the complex matrix of biofilm communities and promptly kill the bacteria. In addition, silver nanoparticles are more potent than ionic silver, as the latter is usually inactivated by complexation and precipitation and in addition are cytotoxic to human cells (Kora and Arunachalam, 2011). Finally, due to the multiple and simultaneous mechanisms of AgNP action the pathogen is less likely to develop resistance against these particles (Klueh et al., 2000; Mathur et al., 2018; Pompilio et al., 2018). Even though the antimicrobial effect of AgNPs alone was quite remarkable, a combination with one or more antibiotics would considerably strengthen the treatment and would likely overcome bacterial resistance. Combinations of drugs, such as beta-lactams and aminoglycosides are already been used to treat $P$. aeruginosa infections in humans (Fritzenwanker et al., 2018).

The exact mechanism through which AgNPs kill bacteria is still unclear. Two different mechanisms have been proposed: killing by contact and $\mathrm{Ag}^{+}$-mediated death. In the former, a strong interaction between AgNPs and the peptidoglycan layer takes place, which eventually generates openings in the cell wall resulting in the extravasation of the cellular content (Sondi and Salopek-Sondi, 2004; Rai et al., 2012; Franci et al., 2015). Another mechanism suggests that AgNPs penetrate the microbial cell, where they interact with cellular structures and biomolecules, such as proteins, lipids, and DNA. The interaction of these macromolecules with the AgNPs leads to bacterial dysfunction and ultimately death. In particular, AgNPs interact with ribosomes resulting in their denaturation and consequently protein synthesis inhibition (Morones et al., 2005). AgNPs also have the ability to produce high levels of reactive oxygen species (ROS), such as hydrogen peroxide, anion superoxide, hydroxyl radical, hypochlorous acid and singlet oxygen (Kalishwaralal et al., 2010), that attack bacterial structures and macromolecules. The immune response of the larvae fight the remaining bacteria by synthesizing hemocytes (Mizerska-Dudka and Andrejko, 2014), antimicrobial peptides, lysozyme and by activating the PO cascade (Morones et al., 2005; Tokura et al., 2014; Wojda, 2017).

In conclusion, here, we presented for the first time a thorough analysis of the antipseudomonal effect of biogenic AgNPs on G. mellonella larvae. A prophylactic treatment with silver nanoparticles efficiently protected G. mellonella from bacterial infection by killing the invading bacteria and possibly by regulating the larva's immune response. Based on the analysis of 6 endpoints: survival assay, bacterial load, quantification and qualification of hemocytes, phenoloxidase activity and quantification of nodules, the present work validated the use of G. mellonella as a model for testing antipseudomonal drugs and for the study of bacterial pathogenesis and host response.

\section{DATA AVAILABILITY STATEMENT}

The raw data supporting the conclusions of this article will be made available by the authors, without undue reservation.

\section{AUTHOR CONTRIBUTIONS}

LT and LG contributed to this study, by designing and conducting all experiments, and helped drafting the manuscript. FS synthesized and analyzed the physico-chemical activities of silver nanoparticles. MC conducted the microscopic analyses. CT 
gave support and helped drafting the manuscript. BS coordinated the study and drafted the manuscript. All authors contributed to the article and approved the submitted version.

\section{FUNDING}

This work was supported by FAPESP [2016/08730-6 (CT), 2012/24105-3 (MC), and 2011/07775-2 (BS)], CNPq, and CAPES. LT and LG were supported by FAPESP scholarships 2015/06547-7 and 2014/09143-1. BS and CT were supported by CNPq productivity scholarships.

\section{REFERENCES}

Andrejko, M., Zdybicka-Barabas, A., and Cytryńska, M. (2014). Diverse effects of Galleria mellonella infection with entomopathogenic and clinical strains of Pseudomonas aeruginosa. J. Invertebr. Pathol. 115, 14-25. doi: 10.1016/j.jip.2013.10.006

Banville, N., Browne, N., and Kavanagh, K. (2012). Effect of nutrient deprivation on the susceptibility of Galleria mellonella larvae to infection. Virulence 3, 497-503. doi: 10.4161/viru.21972

Beeton, M., Alves, D., Enright, M., and Jenkins, A. (2015). Assessing phage therapy against Pseudomonas aeruginosa using a Galleria mellonella infection model. Int. J. Antimicrob. Agents 46, 196-200. doi: 10.1016/j.ijantimicag.2015.04.005

Bergin, D., Murphy, L., Keenan, J., Clynes, M., and Kavanagh, K. (2006). Pre-exposure to yeast protects larvae of Galleria mellonella from a subsequent lethal infection by Candida albicans and is mediated by the increased expression of antimicrobial peptides. Microbes Infect. 8, 2105-2112. doi: 10.1016/j.micinf.2006.03.005

Browne, N., Heelan, M., and Kavanagh, K. (2013). An analysis of the structural and functional similarities of insect hemocytes and mammalian phagocytes. Virulence 4, 597-603. doi: 10.4161/viru.25906

Browne, N., and Kavanagh, K. (2013). Developing the potential of using Galleria mellonella larvae as models for studying brain infection by Listeria monocytogenes. Virulence 4, 271-2. doi: 10.4161/viru.24174

Coates, C. J., Lim, J., Harman, K., Rowley, A. F., Griffiths, D. J., Emery, H., et al. (2019). The insect, Galleria mellonella, is a compatible model for evaluating the toxicology of okadaic acid. Cell Biol. Toxicol. 35, 219-232. doi: 10.1007/s10565-018-09448-2

Cutuli, M. A., Petronio, G., Vergalito, F., Magnifico, I., Pietrangelo, L., Venditti, N., et al. (2019). Galleria mellonella as a consolidated in vivo model hosts: new developments in antibacterial strategies and novel drug testing. Virulence 10, 527-541. doi: 10.1080/21505594.2019.1621649

da Silva, R. T. P., Petri, M. V., Valencia, E. Y., Camargo, P. H. C., de Torresi, S. I. C., and Spira, B. (2020). Visible light plasmon excitation of silver nanoparticles against antibiotic-resistant Pseudomonas aeruginosa. Photodiagn. Photodyn. Therapy 31:101908. doi: 10.1016/j.pdpdt.2020.101908

Decraene, V., Ghebrehewet, S., Dardamissis, E., Huyton, R., Mortimer, K., Wilkinson, D., et al. (2018). An outbreak of multidrug-resistant Pseudomonas aeruginosa in a burns service in the North of England: challenges of infection prevention and control in a complex setting. J. Hosp. Infect. 100, e239-e245. doi: 10.1016/j.jhin.2018.07.012

Desbois, A. P., and Coote, P. J. (2012). Utility of greater wax moth larva (Galleria mellonella) for evaluating the toxicity and efficacy of new antimicrobial agents. Adv. Appl. Microbiol. 78, 25-53. doi: 10.1016/B978-0-12-394805-2.00002-6

Dubovskiy, I. M., Whitten, M. M. A., Yaroslavtseva, O. N., Greig, C., Kryukov, V. Y., Grizanova, E. V., et al. (2013). Can insects develop resistance to insect pathogenic fungi? PLoS ONE 8:e60248. doi: 10.1371/journal.pone.0060248

Emerson, J., Rosenfeld, M., McNamara, S., Ramsey, B., and Gibson, R. L. (2002). Pseudomonas aeruginosa and other predictors of mortality and morbidity in young children with cystic fibrosis. Pediatr. Pulmonol. 34, 91-100. doi: 10.1002/ppul.10127

\section{ACKNOWLEDGMENTS}

We thank the Gabriela Taborda Paes de Camargo and Katia Ospino for technical support in the colony farming and toxicity assay of Galleria mellonella.

\section{SUPPLEMENTARY MATERIAL}

The Supplementary Material for this article can be found online at: https://www.frontiersin.org/articles/10.3389/fmicb. 2020.582107/full\#supplementary-material

Fox, C. L. (1968). Silver sulfadiazine-a new topical therapy for Pseudomonas in burns. Arch. Surg. 96:184. doi: 10.1001/archsurg.1968.01330200022004

Franci, G., Falanga, A., Galdiero, S., Palomba, L., Rai, M., Morelli, G., et al. (2015). Silver nanoparticles as potential antibacterial agents. Molecules 20, 8856-8874. doi: $10.3390 /$ molecules 20058856

Fritzenwanker, M., Imirzalioglu, C., Herold, S., Wagenlehner, F. M., Zimmer, K.-P., and Chakraborty, T. (2018). Treatment options for carbapenemresistant gram-negative infections. Deutsch. Arzte. Inter. 115, 345-352. doi: 10.3238/arztebl.2018.0345

Guzman, M., Dille, J., and Godet, S. (2012). Synthesis and antibacterial activity of silver nanoparticles against gram-positive and gram-negative bacteria. Nanomed. Nanotechnol. Biol. Med. 8, 37-45. doi: 10.1016/j.nano.2011.05.007

He, J., Baldini, R. L., Daziel, E., Saucier, M., Zhang, Q., Liberati, N. T., et al. (2004). The broad host range pathogen Pseudomonas aeruginosa strain pa14 carries two pathogenicity islands harboring plant and animal virulence genes. Proc. Natl. Acad. Sci. U.S.A. 101, 2530-2535. doi: 10.1073/pnas.0304622101

Hill, L., Veli, N., and Coote, P. J. (2014). Evaluation of Galleria mellonella larvae for measuring the efficacy and pharmacokinetics of antibiotic therapies against Pseudomonas aeruginosa infection. Int. J. Antimicrob. Agents 43, 254-61. doi: 10.1016/j.ijantimicag.2013.11.001

Jain, J., Arora, S., Rajwade, J. M., Omray, P., Khandelwal, S., and Paknikar, K. M. (2009). Silver nanoparticles in therapeutics: development of an antimicrobial gel formulation for topical use. Mol. Pharmaceutics 6, 1388-1401. doi: $10.1021 / \mathrm{mp} 900056 \mathrm{~g}$

Jander, G., Rahme, L. G., and Ausubel, F. M. (2000). Positive correlation between virulence of Pseudomonas aeruginosa mutants in mice and insects. J. Bacteriol. 182, 3843-3845. doi: 10.1128/JB.182.13.3843-3845.2000

Kalishwaralal, K., BarathManiKanth, S., Pandian, S. R. K., Deepak, V., and Gurunathan, S. (2010). Silver nanoparticles impede the biofilm formation by Pseudomonas aeruginosa and Staphylococcus epidermidis. Coll. Surf. B Biointerfaces 79, 340-4. doi: 10.1016/j.colsurfb.2010.04.014

Karaiskos, I., Antoniadou, A., and Giamarellou, H. (2017). Combination therapy for extensively-drug resistant gram-negative bacteria. Expert Rev. Anti Infect. Ther. 15, 1123-1140. doi: 10.1080/14787210.2017.1410434

Klueh, U., Wagner, V., Kelly, S., Johnson, A., and Bryers, J. D. (2000). Efficacy of silver-coated fabric to prevent bacterial colonization and subsequent device-based biofilm formation. J. Biomed. Mater. Res. 53, 621-631. doi: 10.1002/1097-4636(2000)53:6<621::AID-JBM2>3.0.CO;2-Q

Kora, A. J., and Arunachalam, J. (2011). Assessment of antibacterial activity of silver nanoparticles on Pseudomonas aeruginosa and its mechanism of action. World J. Microbiol. Biotechnol. 27, 1209-1216. doi: 10.1007/s11274-010-0569-2

Labbé, K., and Saleh, M. (2008). Cell death in the host response to infection. Cell Death Diff. 15, 1339-1349. doi: 10.1038/cdd.2008.91

Laureys, D., and De Vuyst, L. (2014). Microbial species diversity, community dynamics, and metabolite kinetics of water kefir fermentation. Appl. Environ. Microbiol. 80, 2564-72. doi: 10.1128/AEM.03978-13

Lee, D. G., Urbach, J. M., Wu, G., Liberati, N. T., Feinbaum, R. L., Miyata, S., et al. (2006). Genomic analysis reveals that Pseudomonas aeruginosa virulence is combinatorial. Genome Biol. 7:R90. doi: 10.1186/gb-2006-710 -r90 
Liao, S., Zhang, Y., Pan, X., Zhu, F., Jiang, C., Liu, Q., et al. (2019). Antibacterial activity and mechanism of silver nanoparticles against multidrug-resistant. Int. J. Nanomed. 14, 1469-1487. doi: 10.2147/IJN.S191340

Magiorakos, A.-P., Srinivasan, A., Carey, R. B., Carmeli, Y., Falagas, M. E., Giske, C. G., et al. (2012). Multidrug-resistant, extensively drug-resistant and pandrug-resistant bacteria: an international expert proposal for interim standard definitions for acquired resistance. Clin. Microbiol. Infect. 18, 268-81. doi: 10.1111/j.1469-0691.2011.03570.x

Markowska, K., Grudniak, A. M., and Wolska, K. I. (2013). Silver nanoparticles as an alternative strategy against bacterial biofilms. Acta Biochim. Pol. 60, 523-30. doi: 10.18388/abp.2013_2016

Mathee, K. (2018). Forensic investigation into the origin of pseudomonas aeruginosa pa14 - old but not lost. J. Med. Microbiol. 67, 1019-1021. doi: 10.1099/jmm.0.000778

Mathur, P., Jha, S., Ramteke, S., and Jain, N. K. (2018). Pharmaceutical aspects of silver nanoparticles. Art. Cells Nanomed. Biotech. 46(Suppl 1):115-126. doi: 10.1080/21691401.2017.1414825

Miller, J. H. (1992). A Short Course in Bacterial Genetics: A Laboratory Manual and Handbook for Escherichia coli and Related Bacteria. Cold Spring Harbor, NY: Cold Spring Harbor Laboratory.

Miyata, S., Casey, M., Frank, D. W., Ausubel, F. M., and Drenkard, E. (2003). Use of the Galleria mellonella caterpillar as a model host to study the role of the type III secretion system in Pseudomonas aeruginosa pathogenesis. Infect. Immun. 71, 2404-2413. doi: 10.1128/IAI.71.5.2404-2413.2003

Mizerska-Dudka, M., and Andrejko, M. (2014). Galleria mellonella hemocytes destruction after infection with Pseudomonas aeruginosa. J. Basic Microbiol. 54, 232-46. doi: 10.1002/jobm.201200273

Morones, J. R., Elechiguerra, J. L., Camacho, A., Holt, K., Kouri, J. B., Ramírez, J. T., et al. (2005). The bactericidal effect of silver nanoparticles. Nanotechnology 16, 2346-53. doi: 10.1088/0957-4484/16/10/059

Nour El Din, S., El-Tayeb, T. A., Abou-Aisha, K., and El-Azizi, M. (2016). In vitro and in vivo antimicrobial activity of combined therapy of silver nanoparticles and visible blue light against Pseudomonas aeruginosa. Int. J. Nanomed. 11, 1749-1758. doi: 10.2147/IJN.S102398

Panáček, A., Kvítek, L., Smékalová, M., Večerová, R., Kolár, M., Röderová, M., et al. (2018). Bacterial resistance to silver nanoparticles and how to overcome it. Nat. Nanotechnol. 13, 65-71. doi: 10.1038/s41565-017-0013-y

Pompilio, A., Geminiani, C., Bosco, D., Rana, R., Aceto, A., Bucciarelli, T., et al. (2018). Electrochemically synthesized silver nanoparticles are active against planktonic and biofilm cells of Pseudomonas aeruginosa and other cystic fibrosis-associated bacterial pathogens. Front. Microbiol. 9:1349. doi: $10.3389 /$ fmicb. 2018.01349

Potron, A., Poirel, L., and Nordmann, P. (2015). Emerging broad-spectrum resistance in Pseudomonas aeruginosa and Acinetobacter baumannii: mechanisms and epidemiology. Int. J. Antimicrob. Agents 45, 568-85. doi: 10.1016/j.ijantimicag.2015.03.001

Radzig, M., Nadtochenko, V., Koksharova, O., Kiwi, J., Lipasova, V., and Khmel, I. (2013). Antibacterial effects of silver nanoparticles on gram-negative bacteria: Influence on the growth and biofilms formation, mechanisms of action. Colloids Surf. B 102, 300-306. doi: 10.1016/j.colsurfb.2012.07.039

Rai, M., Deshmukh, S., Ingle, A., and Gade, A. (2012). Silver nanoparticles: the powerful nanoweapon against multidrug-resistant bacteria. J. Appl. Microbiol. 112, 841-852. doi: 10.1111/j.1365-2672.2012.05253.x

Rodríguez-Rojas, A., Oliver, A., and Blázquez, J. (2012). Intrinsic and environmental mutagenesis drive diversification and persistence of Pseudomonas aeruginosa in chronic lung infections. J. Infect. Dis. 205, 121-7. doi: 10.1093/infdis/jir690
Rowan, R., Moran, C., McCann, M., and Kavanagh, K. (2009). Use of Galleria mellonella larvae to evaluate the in vivo anti-fungal activity of [ag 2 (mal)(phen) 3]. Biometals 22:461. doi: 10.1007/s10534-008-9182-3

Schneider, C. A., Rasband, W. S., and Eliceiri, K. W. (2012). NIH Image to ImageJ: 25 years of image analysis. Nat. Methods 9, 671-5. doi: 10.1038/nmeth.2089

Shrivastava, S., Bera, T., Roy, A., Singh, G., Ramachandrarao, P., and Dash, D. (2007). Characterization of enhanced antibacterial effects of novel silver nanoparticles. Nanotechnology 18:225103. doi: 10.1088/0957-4484/18/22/225103

Singh, B. R., Singh, B. N., Singh, A., Khan, W., Naqvi, A. H., and Singh, H. B. (2015). Mycofabricated biosilver nanoparticles interrupt Pseudomonas aeruginosa quorum sensing systems. Sci. Rep. 5:13719. doi: 10.1038/srep13719

Sondi, I., and Salopek-Sondi, B. (2004). Silver nanoparticles as antimicrobial agent: a case study on E. coli as a model for Gram-negative bacteria. J. Colloid Interface Sci. 275, 177-82. doi: 10.1016/j.jcis.2004.02.012

Tokura, A., Fu, G. S., Sakamoto, M., Endo, H., Tanaka, S., Kikuta, S., et al. (2014). Factors functioning in nodule melanization of insects and their mechanisms of accumulation in nodules. J. Insect Physiol. 60, 40-9. doi: 10.1016/j.jinsphys.2013.11.003

Wiehlmann, L., Wagner, G., Cramer, N., Siebert, B., Gudowius, P., Morales, G., et al. (2007). Population structure of Pseudomonas aeruginosa. Proc. Natl. Acad. Sci. U.S.A. 104, 8101-8106. doi: 10.1073/pnas.0609213104

Wojda, I. (2017). Immunity of the greater wax moth Galleria mellonella. Insect Sci. 24, 342-357. doi: 10.1111/1744-7917.12325

Wojda, I., and Jakubowicz, T. (2007). Humoral immune response upon mild heatshock conditions in Galleria mellonella larvae. J. Insect Physiol. 53, 1134-44. doi: 10.1016/j.jinsphys.2007.06.003

Wu, D., Fan, W., Kishen, A., Gutmann, J. L., and Fan, B. (2014). Evaluation of the antibacterial efficacy of silver nanoparticles against Enterococcus faecalis biofilm. J. Endod. 40, 285-290. doi: 10.1016/j.joen.2013.08.022

Wu, G., Liu, Y., Ding, Y., and Yi, Y. (2016). Ultrastructural and functional characterization of circulating hemocytes from Galleria mellonella larva: cell types and their role in the innate immunity. Tissue Cell 48, 297-304. doi: 10.1016/j.tice.2016.06.007

Wypij, M., Czarnecka, J., Świecimska, M., Dahm, H., Rai, M., and Golinska, P. (2018). Synthesis, characterization and evaluation of antimicrobial and cytotoxic activities of biogenic silver nanoparticles synthesized from Streptomyces xinghaiensis OF1 strain. World J. Microbiol. Biotechnol. 34:23. doi: 10.1007/s11274-017-2406-3

Yamasaki, K., Chuang, V. T. G., Maruyama, T., and Otagiri, M. (2013). Albumindrug interaction and its clinical implication. Biochim. Biophys. Acta Gen. Subjects 1830, 5435-5443. doi: 10.1016/j.bbagen.2013.05.005

Yan, X., He, B., Liu, L., Qu, G., Shi, J., Hu, L., et al. (2018). Antibacterial mechanism of silver nanoparticles in Pseudomonas aeruginosa: proteomics approach. Metallomics 10, 557-564. doi: 10.1039/C7MT00328E

Conflict of Interest: The authors declare that the research was conducted in the absence of any commercial or financial relationships that could be construed as a potential conflict of interest.

Copyright (C) 2020 Thomaz, Gustavo de Almeida, Silva, Cortez, Taborda and Spira. This is an open-access article distributed under the terms of the Creative Commons Attribution License (CC BY). The use, distribution or reproduction in other forums is permitted, provided the original author(s) and the copyright owner(s) are credited and that the original publication in this journal is cited, in accordance with accepted academic practice. No use, distribution or reproduction is permitted which does not comply with these terms. 